Revista Iberoamericana. Vol. LXVI, Núm. 190, Enero-Marzo 2000, 93-111

\title{
EGON SCHIELE Y LOS CUADERNOS DE DON RIGOBERTO DE MARIO VARGAS LLOSA: ICONOTEXTUALIDAD E INTERMEDIALIDAD
}

\author{
POR \\ Guadalupe Martí-Peña \\ The Pennsylvania State University
}

“De esta novela hablará todo el mundo. En todo el mundo”. Estas palabras, impresas en tinta roja sobre la contraportada del libro Los cuadernos de don Rigoberto (1997), ${ }^{1}$ auguran a la última novela de Mario Vargas Llosa un éxito editorial rotundo. En ellas resuenan curiosamente las pronunciadas - casi setenta años antes - por Egon Schiele en su lecho de muerte, según el testimonio de su cuñada, Adele Harms: "The war is over and I must go. My paintings shall be shown in all the museums of the world” (Wilson 7).

Esta coincidencia entre el escritor peruano-español y el pintor austriaco no es del todo casual. La vida y obra pictórica de Egon Schiele (1890-1918) urden el entramado textual, narrativo y visual de Los cuadernos. Entender la novela de Vargas Llosa y su apropiación de Schiele supone, por una parte, entender la vida y obra del pintor austríaco; por otra, entender el modo en que el texto narrativo las (re)presenta y la función que desempeñan dentro del mismo.

Dentro del campo de estudios que se ocupa de la correspondencia entre diversas manifestaciones artísticas, bautizado en investigaciones internacionales recientes como “Artes comparativas”, los debates más antiguos son los tocantes a las relaciones entre textos literarios y pictóricos. Sin embargo, en cuanto parte de la disciplina académica de la teoría literaria, este debate es relativamente más nuevo (Lund 1). La interpretación de Los cuadernos en relación con el arte pictórico de Schiele se convierte así en lo que Peter Wagner ha dado en llamar "an intertextual or intermedial venture” (10). Wagner define el término intermediality como una división de la intertextualidad, al considerar que las imágenes al igual que los textos son retóricos y, por tanto, emplean signos verbales y/o icónicos para comunicar sentido. Intermediality remite, por lo tanto, al uso intertextual de un medio (la pintura) en otro medio (la prosa ficticia) y viceversa (17). Este crítico nos advierte, también, del riesgo que existe al emprender este tipo de investigaciones:

The main reason for the absence of studies in intermediality is, of course, the reluctance of many scholars to work in what they consider to be alien territory. [...] But if we are to overcome the "correspondence-of-the-arts approach" that assumes a "mutual illumination" (which still rules the fields of both literary criticism and art history) in the study of

${ }^{1} \mathrm{~A}$ partir de este momento el título aparecerá abreviado como Los cuadernos. Todas las citas provienen de la edición Los cuadernos de don Rigoberto. 
iconotexts while turning a blind eye to the warfare involving difference and différance in each medium and between the media, we should move from the theoretical ground prepared by Bal, Bryson, Hansen-Löve, Zander, Reader, Plett, and Fowler, to practical interpretations that take into account the intermedial nature of iconotexts. I propose a name or tag to such enterprises — let us call them studies in intermediality (18).

Mi objetivo es analizar la relación que se establece en Los cuadernos entre los sistemas semióticos de la pintura y de la escritura, definidos por Bryan Wolf como "signifying systems and rhetorical constructs that we try to appropriate" (188-91). El enfoque que propongo persigue una interpretación práctica que tenga en cuenta la naturaleza intermedial o intermediática de los iconotextos, vocablo éste último aplicable a pinturas que contienen escritura o palabras, y a textos literarios que funcionan con imágenes: "iconotext refers to an artifact in which the verbal and the visual signs mingle to produce rhetoric that depends on the co-presence of words and images" (Wagner 16-17). Como indica Hans Lund, raras veces un texto literario transformador de otro pictórico, tiene como objetivo primordial y único la interpretación de una pintura per se (como sería el caso de los historiadores o críticos del arte). No basta, pues, con analizar las cualidades pictóricas de un texto narrativo o identificar los iconotextos que de forma patente o latente operan dentro del mismo. Es necesario determinar, también, las funciones que desempeñan dichos iconotextos con relación al todo narrativo en el que obran (10): "picture-transforming texts have not only a descriptive function but also interpretative, commenting, and supplementary functions" (Lund 17). Según pretendo demostrar en este artículo, la vida y el arte pictórico de Egon Schiele no funcionan como mero gesto decorativo o simple telón de fondo en Los cuadernos, sino que operan intrínsecamente en diferentes niveles del libro. ${ }^{2}$ Examinaré, en primer lugar, algunas de las semejanzas y diferencias que esta novela guarda con Elogio de la madrastra (1988, en adelante, Elogio), novela erótica del mismo autor, de la que Los cuadernos es continuación. La implantación de reproducciones pictóricas en las páginas de estos dos libros actúa en cada uno de ellos de modo muy distinto, tanto estilística como pragmáticamente, es decir, en cuanto al objeto estético en sí se refiere y en cuanto a su relación con el sujeto que lo percibe. En segundo lugar comentaré la imagen de la cubierta del libro, desde la que se anuncia ya el destacado lugar que ocupa Schiele en el mundo ficticio de Los cuadernos. Finalmente, analizaré algunas de las funciones que la vida y obra pictórica de Schiele asumen dentro de los planos diegético, temático e ideológico de la novela. ${ }^{3}$

Antes de iniciar el análisis comparativo entre Elogio y Los cuadernos conviene resumir someramente el argumento de esta saga familiar que se inaugura con Elogio. Los personajes

${ }^{2}$ En Los cuadernos abundan las referencias a pintores y obras pictóricas: Szyszlo, Balthus, Botero, Klimt, Rubens, Courbet, Goya, Degas, Ribera, Renoir, Warhol, Kahlo, Vermeer, Picasso, Ingres, Bacon, Arcimboldo, Tiziano, Van Gogh, Botticelli, entre otros. Sin embargo, en este estudio voy a examinar únicamente cómo opera la vida y obra de Schiele en esta novela.

${ }^{3}$ En The Visual Arts, Pictorialism, and the Novel: James, Lawrence, and Woolf, Marianna Torgovnick distingue cuatro funciones de las artes visuales en la novela: decorativa, biográfica, ideológica e interpretativa. Empleo el término diegético en el amplio sentido que le confiere Gérard Genette, al referir tanto a la descripción como a la narración en sí (Figures II, 56-61). 
centrales de Elogio, Rigoberto, Lucrecia, Alfonso (Foncín, Fonchito) y Justiniana saltan a las páginas de Los cuadernos para continuar una historia de placeres e intimidades compartidos, que se desenvuelve dentro del marco legítimo y legitimador de la familia y del lecho conyugal. En Elogio se relata el proceso de seducción de Lucrecia por parte de su hijastro, Fonchito, un niño de aspecto angélico pero comportamiento maquiavélico. Al enterarse Rigoberto de la relación incestuosa que mantienen su mujer e hijo, expulsa a Lucrecia de la casa que había hecho construir específicamente para sus libros y para ella. Los cuadernos se abre con la llegada de Fonchito a la casa de su madrastra con el fin de conseguir su perdón. Sus visitas se hacen cada vez más frecuentes, ya que Lucrecia resulta ser una interlocutora ejemplar para el relator ávido que es Fonchito. Sus conversaciones giran siempre en torno a la vida y obra de Schiele, el pintor predilecto del niño. Mientras tanto Rigoberto se consuela de la ausencia de su mujer fantaseando sobre ella en el templo solitario de su estudio, rodeado de iconos de la literatura y pintura erótica occidental, principalmente. ${ }^{4}$ Fonchito se propone amistarlos tras casi un año de separación y para ello urde un plan, que consiste en enviarles anónimos haciéndoles creer que es el otro quien se los envía. Sus maquinaciones surten efecto y el epílogo titulado “Una familia feliz” marca el cierre optimista de la novela. Un final feliz que no logra disipar, sin embargo, ese nubarrón que sigue amenazando la paz matrimonial de la pareja: Fonchito.

La imagen que se plasma sobre la cubierta del libro Los cuadernos, en la que aparece un camisón de seda negra extendido sobre el borde de una cama, tiende un puente inequívoco entre esta novela y Elogio. Para ello, basta recordar la manera en que se describía a la madrastra al comienzo de Elogio: "Había olvidado echarse encima la bata, iba desnuda bajo el ligero camisón de dormir de seda negra y sus formas blancas, ubérrimas, duras todavía, parecían flotar en la penumbra entrecortada por los reflejos de la calle” (16, énfasis mío). Al describir la escena recién citada, la voz narradora funciona como un lápiz o pincel que fuera delineando formas, coloreando volúmenes o difuminando contornos. Esta descripción revela, por una parte, las implicaciones eróticas de la palabra: “The need to explicate form and to articulate the collocation of colors, brings one closer to an acceptable pornography of discourse" (Freedberg 318). ${ }^{5}$ Por otra, explica la desconfianza y el temor frente al poder de las imágenes, que ha dado lugar a discursos represores o anuladores de lo que se considera un peligro o amenaza visual: "The use of colour in rhetoric and painting are potentially dangerous (because they serve as means of seduction) and must be held in check” (Wagner 31). Forma, color, composición, luz, encuadre y perspectiva, son algunos de los elementos pictóricos que impregnan el discurso narrativo y descriptivo de Elogio y Los cuadernos. Esta apropiación que el discurso narrativo hace de la terminología y técnicas del medio pictórico, haciendo visible el discuso verbal, erotizando la palabra al darle color,

\footnotetext{
${ }^{4}$ La colección de Rigoberto incluye, también, algunas reproducciones de obras del pintor y grabador japonés, Utamaro (1753-1806), y de grabados eróticos japones del período Meiji.

${ }^{5}$ En cuanto al debate entre lo que diferencia o no, pornografía, erotismo, obscenidad, comparto la opinión de Freedberg: "After reading through the arguments for and against pornography I came to agree with Susan Sontag that it is not helpful to separate pornography from the realm of literature and that the stimulation of sexual desire can be a legitimate aim of high literature as well as pornography" (12).
} 
forma y volumen, ${ }^{6}$ es una de las estrategias estilísticas que — según Lund— caracteriza los textos en los que se llevan a cabo transformaciones literarias de obras pictóricas: “actually, with no direct connection to any actual or fictitious picture, it (the text) may even try to convey the structuring principles or the characteristics of style from pictorial art to verbal form” (10).

Elogio consta de catorce capítulos, un epílogo y una sección intitulada “pinacoteca” en la que se listan los títulos de los cuadros reproducidos en el libro. Cada dos capítulos se inserta la lámina de un cuadro que recobrará vida en el capítulo siguiente, mediante la transformación de una de sus figuras en narrador(a) de la escena pictórica precedente. La organización narrativa del libro alterna capítulos en los que la historia de la familia es relatada en tercera persona por un narrador omnisciente, mediador del diálogo de los personajes, con capítulos en los que el discurso es proferido en primera persona por una instancia narradora doble, resultante de la fusión de uno de los personajes de la novela con una de las figuras de los cuadros.

Los cuadernos se compone de nueve capítulos y un epílogo. Cada capítulo contiene tres subdivisiones (excepto el segundo que consta de cuatro) y al final de cada uno se implanta la reproducción en blanco y negro de un dibujo o pintura de Egon Schiele. La organización del libro es igualmente dual. Por una parte, en el texto que abre cada capítulo un narrador extradiegético omnisciente relata las visitas de Fonchito a la madrastra, mediando sus conversaciones sobre la vida y obra de Schiele. Por otra parte, los textos restantes remiten tanto al contenido de los cuadernos de Rigoberto (citas, cartas y anotaciones escritas en primera persona), como a las fantasías que estrena este personaje en el teatro de su imaginación, referidas por un narrador-cómplice que combina la narración con el diálogo, entrometiéndose en lo narrado a modo de voyeur.

Tanto en Elogio como en Los cuadernos, Vargas Llosa recurre a la técnica de la reduplicación interna. La composición erótica que escribe Fonchito para su colegio lleva por título "Elogio de la madrastra". Los cuadernos contiene en su interior múltiples referencias a los cuadernos que Rigoberto atesora en su estudio, caracterizados al igual que el libro continente por su índole heterogénea y fragmentaria. Ambas novelas funcionan como iconotextos al producirse en ellas la inter-penetración de signos verbales e icónicos. Al lector o lectora se les induce a leer el texto narrativo vis-à-vis una serie de reproducciones pictóricas que forman parte integral del libro. La pinacoteca de Elogio consta de las siguientes obras:

(1) “Candaules, Rey de Lidia” (cap. 2): Jacob Jordaens, Candaules, rey de Lidia, muestra su mujer al primer ministro Giges (1648), óleo sobre tela, Museo Nacional de Estocolmo.

(2) “Diana después de su baño” (cap. 5): François Boucher, Diana después de su baño (1742), óleo sobre tela, Museo del Louvre, París.

(3) "Venus con amor y música” (cap.7): Tiziano Vecellio, Venus con el Amor y la Música, óleo sobre tela, Museo del Prado, Madrid.

\footnotetext{
${ }^{6}$ Me gustaría comentar que en Los cuadernos, las palabras no solamente adquieren volumen, forma y color, sino que recuperan también el olor, el sabor y el tacto. Elogio y Los cuadernos, son narrativas visuales en las que se rinde honor a los cinco sentidos.
} 
(4) “Semblanza de humano” (cap. 9): Francis Bacon, Cabeza I (1948), óleo y témpera, colección Richard S. Zeisler, Nueva York.

(5) “Laberinto de amor” (cap.12): Fernando de Szyszlo, Camino a Mendieta 10 (1977), acrílico sobre tela, colección particular.

(6) "El joven rosado" (cap. 14): Fra Angelico, La Anunciación (c.1437), fresco, Monasterio de San Marco, Florencia.

Estos óleos y el último fresco, pertenecientes a la colección privada de Rigoberto, se intercalan cada dos capítulos del libro y funcionan como enlace temático y visual entre los capítulos que los preceden y suceden. Los capítulos consecutivos a cada uno de los cuadros, son descripciones (ekfrasis) y dramatizaciones de dichas escenas pictóricas, a cargo de voces que, travestidas, dan rienda suelta a las fantasías eróticas de Rigoberto. Los cuadros toman así vida discursiva.

Sin embargo, si en Elogio la transformación literaria de las obras pictóricas consiste fundamentalmente en la transformación de lo estático del cuadro en lo dinámico del discurso narrativo, en Los cuadernos su transformación opera de modo inverso, como argumentaré a continuación.

Al final de cada uno de los nueve capítulos y del epílogo de que consta la novela, se reproduce una pintura o dibujo de Schiele:

pág. 30: "Self-Portrait in Crouching Position” (gouache y lápiz, 1913)

pág. 74: “Two Nude Girls Embracing” (carboncillo, 1918)

pág. 112: “Two Girls, Lying Entwined” (gouche y lápiz, 1915)

pág. 149: "Sleeping Girls” (carboncillo, 1918)

pág. 192: "Portrait of Erich Lederer, Bending Down” (lápiz, 1912)

pág. 231: "Double Self-Portrait” (gouche, acuarela y lápiz, 1915)

pág. 270: "Reclining Female Nude” (carboncillo, 1916)

pág. 310: “Schiele, Drawing a Nude Model before a Mirror” (lápiz, 1909)

pág. 354: "Man and Woman” (carboncillo, 1917)

pág. 384: “Standing Male Nude with Red Loincloth” (1914)

La transformación literaria que sufren los textos pictóricos en Elogio y Los cuadernos, es de signo inverso. En Elogio — como acabo de señalar — cada uno de los personajes de la novela recreaba discursivamente la imagen pictórica precedente, dinamizando lo estático y verbalizando lo visual. En Los cuadernos, en cambio, Lucrecia y Justiniana concretizan visualmente la descripción verbal que Fonchito hace de los dibujos de Schiele. Bajo la dirección de Fonchito, Lucrecia y su criada imitan las poses de las figuras retratadas por el pintor. A diferencia de la anterior novela, en Los cuadernos el flujo del devenir narrativo se detiene y se suspende en un instante, lo dinámico se vuelve estático. La fijación del devenir más allá del tiempo cronológico o histórico como imperativo para el alcance de la plenitud y perfección, se ilustra, por ejemplo, en la descripción de la siguiente escena en la que Fonchito contempla a Lucrecia imitando la pose de la modelo del cuadro Desnudo reclinado con medias verdes:

Desde la alfombra, sentado con las piernas cruzadas como un oriental, la miraba arrobado, la boca entreabierta, sus ojos un par de lunas llenas, en éxtasis. La señora Lucrecia dejó pasar cinco, diez, quince segundos, quietecita, contagiada de la solemnidad con que el 
niño tomaba el juego. Algo ocurría. ¿La suspensión del tiempo? ¿El presentimiento del absoluto? ¿El secreto de la perfección artística?” (79, énfasis mío)

Mientras que en Elogio el arte recobraba vida, en Los cuadernos la vida se hace arte, de manera que el acto de amor se desanimaliza gracias a la pátina de la estética, convirtiéndose en acto creativo (284). La vida ha de imitar el arte, es decir, el devenir de la vida debe congelarse y perpetuarse en ese instante de perfección estética y estática, que solamente el cuadro puede alcanzar.

Esta operación subversiva se extiende - en clave de humor - a todo tipo de ortodoxia o utopía social comunitaria de “estos tiempos municipalizados de la vida” (125): asociaciones o grupos feministas, ecológistas, deportivos, religiosos, etc., para construir paradójicamente otra ortodoxia o utopía de índole libertaria e individual, en la que todo cabe —incluso el promiscuo partouze ${ }^{7}$ — a condición de que se haga en nombre del placer, de la belleza o del individuo (adulterio, bisexualidad, homosexualidad, lesbianismo, sodomía, pedofilia, masoquismo, fetichismo, narcisismo, bestialismo, escatología, voyeurism, etc.):

\begin{abstract}
estoy teóricamente a favor de que los seres humanos hagan el amor al derecho o al revés, solos o por parejas o en promiscuos contubernios colectivos (ajjjj), de que los hombres copulen con hombres y las mujeres con mujeres y ambos con patos, perros, sandías, plátanos o melones y todas las asquerosidades imaginables si las hacen de común acuerdo y en pos del placer, no de la reproducción, accidente del sexo al que cabe resignarse como un mal menor, pero de ninguna manera santificar como justificación de la fiesta carnal (esta imbecilidad de la Iglesia me exaspera tanto como un match de básquet) (126).
\end{abstract}

Esta postura estético-ética de Rigoberto se radicaliza hasta el extremo de llegar a sentenciar que "toda actividad que no contribuye al placer es despreciable" (167).

Rigoberto acomete frenéticamente esta operación demoledora de cualquier ideología colectivista o práctica colectiva que transforme al individuo en ese abominable hombrerebaño u hombre-masa, salvándose sólo de sus feroces martillazos anti-institucionales la institución matrimonial y el cánon clásico de belleza, sus dos máximos paradigmas ético y estético. Su vida se convierte en una lucha sin cuartel contra la desindividualización que amenaza con extinguir “el reinado del hombre libre y soberano” que él ejemplifica: “estoy movilizado en zafarrancho de combate, con mis cinco sentidos y las veinticuatro horas del día, para demorar lo más que pueda, en lo que a mí concierne, esa derrota existencial” (164).

Además de esta inversión de jerarquías entre la vida y el arte que mencioné anteriormente (el arte se hace vida o la vida se hace arte), una segunda diferencia destacable entre Elogio y Los cuadernos se refiere al modo en el que Vargas Llosa implanta las reproducciones pictóricas sobre las páginas de estos libros, y la distinta función que, por lo tanto, asumen en cada uno de ellos. En Elogio, las reproducciones de los lienzos figuraban en la página anterior a los capítulos que servían de ekfrasis. Además, estas reproducciones ocupaban la casi totalidad de la página en blanco o la mitad superior de la misma, sin que se inscribiera

\footnotetext{
${ }^{7}$ Actividad descartada anteriormente por Rigoberto como "equivalente al colectivismo político y social” en el terreno de las relaciones sexuales (249), pero que ahora parece despenalizar, probando la condición contradictoria del personaje-protagonista.
} 
en ellas texto alguno, solamente los números a pie de página que permitían identificar las ilustraciones en la pinacoteca. Todos estos óleos se enmarcaban dentro de un formato cuadrado o rectangular que fijaba sus límites, además del encuadre suplementario constituido por los bordes de la página en blanco en la que se insertaban. Las reproducciones de los dibujos de Schiele, en los que el pintor utiliza y combina diversas técnicas (carboncillo, lápiz, pinturas a la aguada y acuarelas) se incluyen, en cambio, al final de los capítulos, coexistiendo texto e imagen. Los dibujos se reproducen desprovistos de marco, salvo el constituido por los bordes de la página y del texto escrito. Irónicamente, estos dibujos que parecen flotar libremente en el blanco de la página suscitan una profunda sensación de encierro y confinamiento. Las reproducciones de estos dibujos, los trazos que definen esos cuerpos entrelazados o dislocados en posturas desencajadas, parecen ir a la deriva en el mar solitario de la página en blanco.

Al hablar de la compleja personalidad de Schiele y su tendencia neurótica, Frank Witford hace alusión a la importancia que el pintor otorgaba a la firma de sus cuadros:

Schiele's attitude to himself is also reflected in the almost neurotic attention he paid to his signature and handwriting. Even as a child he signed almost everything he drew, often writing his name in a very mannered fashion. For some time he experimented with a variety of eye-catching signatures. This was no doubt partly due to the attention paid to their signatures by all the Secession artists, but it was equally the result of Schiele's deep involment with himself. There is scarcely painting or drawing in which Schiele's signature is not prominently placed or so positioned that it becomes an essential part of the design or composition (41).

Los dibujos de Schiele insertados al final del cuerpo textual parecen funcionar como la firma del pintor(a) sobre su lienzo o la del escritor(a) al final de una carta, es decir, como un seño autoritativo. Sin embargo, si entendemos el valor de toda firma como garantía de singularidad y autenticidad, este gesto autógrafo pierde su aura con la reproductividad técnica masiva. ${ }^{8}$ Santos Zunzunegui comenta respecto a este fenómeno lo siguiente:

La reproducción técnica hace que su valor cultural sea progresivamente dominado por su valor exhibitivo, cambiando la relación del público con aquéllas, de tal forma que la cantidad puede convertirse en calidad y el crecimiento masivo del número de espectadores [...] muestra el surgimiento, por primera vez, de las posibilidades de una recepción simultánea y colectiva. A través de la reproducción tecnológica — que borra la antigua distinción entre original y copia — la fugacidad y la repetición sustituyen a la singularidad y la duración, típica de las imágenes únicas (108).

Aunque Rigoberto defiende el sello autoritativo como garantía artística frente al anonimato del Arte Popular ("no hay arte impersonal, señor patriota" 251) y como muestra, además, de heroísmo ("Morir firmando con nombre y apellido propios, tener una muerte personal” 251), Vargas Llosa y Los cuadernos se alían con el pop-art y otras manifestaciones

${ }^{8}$ En "La obra de arte en la época de su reproductibilidad técnica”, Walter Benjamin analiza el impacto que la reproducción tecnológica ha causado en cuanto a la concepción misma del arte y sus funciones dentro de las sociedades post-industriales modernas. 
artísticas posmodernas, para poner en tela de juicio las nociones de originalidad y singularidad en cuanto imperativos estéticos desde el Romanticismo. Todos los dibujos de Schiele se reproducen en blanco y negro aunque el original contenga color. Mientras el discurso verbal de Los cuadernos se cromatiza al hacer uso de la retórica pictórica, los dibujos y acuarelas de Schiele se descromatizan o verbalizan reducidas al blanco y negro de la escritura. Respecto a Rigoberto, la inclusión de estas reproducciones en el libro puede conducir a ciertas implicaciones significativas de índole contradictoria. Por una parte, la antigua concepción de la obra de arte como “manifestación irrepetible de lejanía” (Benjamin 27), da paso en esta era del simulacro y la copia a ese “acercamiento espacial y humano” del que hablaba Zunzunegui, que hace que Rigoberto llegue a sentir junto a él el cuerpo tan distante de su mujer. Por otra parte, la reproductividad técnica masiva hace que la recepción del arte se convierta en uno de esos tipos de experiencias colectivas contra las que Rigoberto lanza sus diatribas más violentas.

La tercera distinción importante con respecto a la inclusión de obras pictóricas en ambas narrativas visuales, radica en el hecho de que Vargas Llosa no identifica los dibujos de Schiele implantados en las páginas de Los cuadernos, como lo hiciera en la pinacoteca de Elogio. Al desproveer los dibujos y acuarelas de sus títulos, a los lectores y lectoras de la novela se les incita a (h)ojear los catálogos de obras del pintor con el fin de identificarlos. La contemplación de sus 334 pinturas, 2503 dibujos y acuarelas, 21 libretas de dibujos y sus 17 gráficos, ${ }^{9}$ hace de los lectores y lectoras de la novela puros voyeurs, quienes comparten con Rigoberto y su mujer el goce que a éstos les produce su pasatiempo favorito: (h)ojear los libros y grabados de pintura erótica de la colección privada de Rigoberto.

La naturaleza iconotextual de Los cuadernos se anuncia ya desde la cubierta misma del libro diseñada por Deo Volente. La imagen de la portada muestra el ángulo de una alcoba, bañada por el haz de luz que desciende en diagonal por una puerta lateral entreabierta. En primer plano a la izquierda, se deja entrever el borde de una cama cubierto por una bata de raso color crema, encima de la cual se extiende un camisón de seda negro. En el centro, sobre los pliegues de la tela vaporosa de la bata que se desborda de la cama, reposa un zapato rojo de tacón alto. Al fondo, bajo el cono de luz que penetra por el vano de la puerta, destaca apoyado sobre la pared un cuadro de Schiele de 1910: El retrato de Herbert Rainer. Esta utilización de la luz como medio de resaltar y encerrar el objeto sobre el cual se proyecta, es una técnica pictórica recurrente en muchos de los fragmentos descriptivos de la novela. Los personajes que son objeto de contemplación aparecen circunscritos dentro de un cono de luz que los aprisiona y aisla de su entorno. Esta luz circular construye un espacio escenográfico claustrofóbico, dentro del cual los personajes interpretan sus papeles frente a un público voyeur, cuyo anonimato es garantizado por la oscuridad de la sala en cuanto al público se refiere, o por la omniscencia narrativa en lo tocante al narrador extradiegético de la novela. Cabe citar a modo de ejemplo la descripción o ekfrasis de uno de esos espectáculos eróticos que imagina Rigoberto, en el que consigue, gracias a sus trucos de ilusionista, ser guionista, actor y espectador al mismo tiempo. En este pasaje descriptivo se ilumina ese "recinto sagrado" que es la cama sobre la que retozan Lucrecia y ese hermano gemelo inventado por Rigoberto, Narciso:

${ }_{9}$ Obras catalogadas en Jane Kallir, Egon Schiele: The Complete Works. 


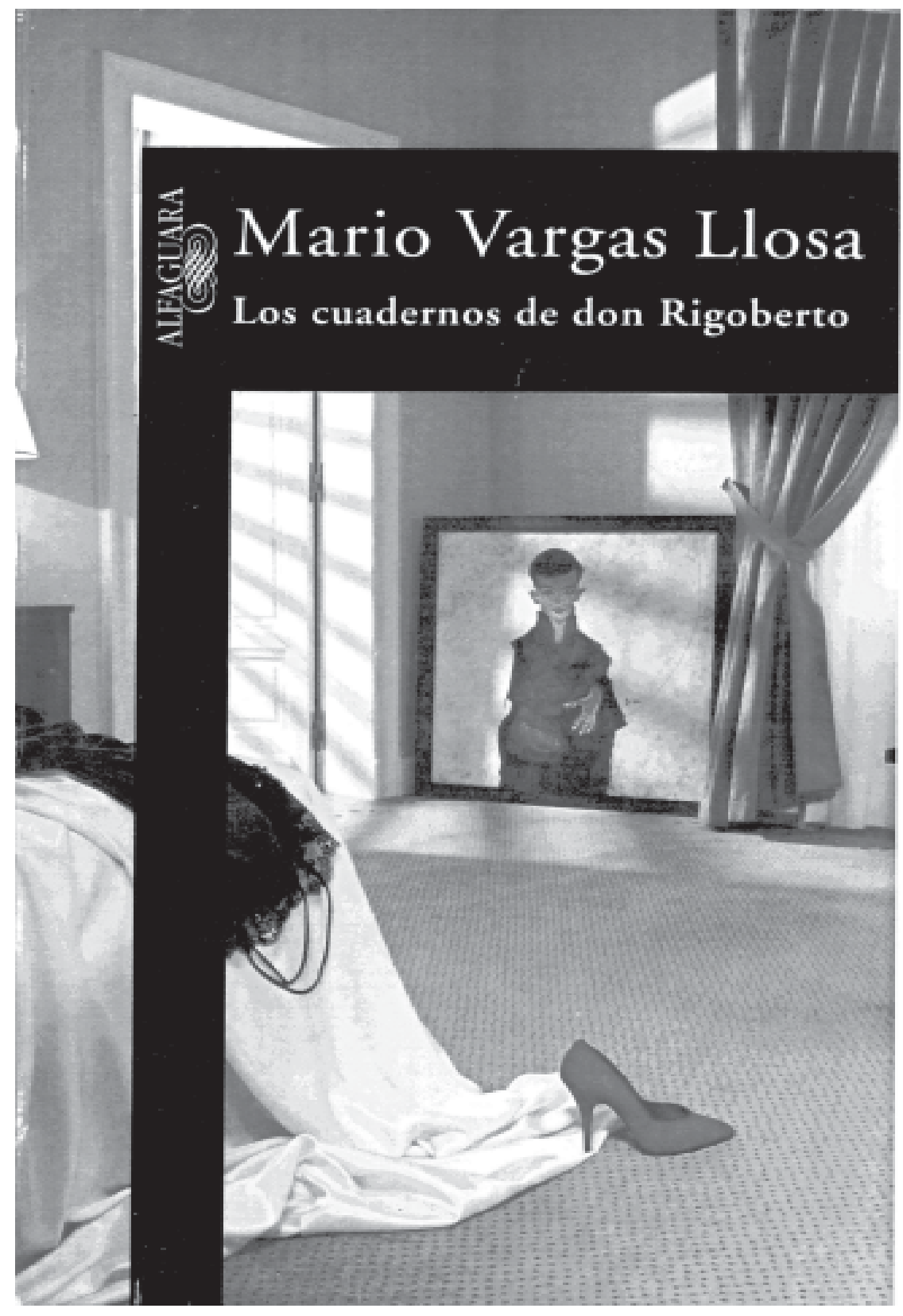


Era anchísima y teatral. En la cónica luz que descendía de una bombilla empotrada en el cielorraso, vio a su hermano corso y Lucrecia fundidos, moviéndose al compás. Hasta él llegó el suave, dialogante jadeo [...] se dejó caer junto a su cuñada en lo que debía ser un largo sofá llenos de cojines, dispuesto de tal modo que la persona sentada allí no perdiera detalle del espectáculo (145, énfasis mío).

Herbert Rainer, el modelo del cuadro de Schiele que aparece en la portada del libro, era el benjamín de un profesor universitario. Según Wilson, este retrato es uno de los menos complicados del pintor. A no ser por el emplazamiento antinatural de las manos y su aspecto incorpóreo, el joven Herbert parece un chico normal con una expresión bastante placentera, que Wilson atribuye al hecho de que este cuadro fuera realizado de encargo. No obstante, El retrato de Herbert Rainer es un cuadro inquietante y perturbador. La posición antinatural de las manos de Herbert y ese cuerpo masivo e informe que las acoge, introducen un elemento desestabilizador dentro de la aparente placidez del modelo. La representación antinatural de sus manos parece sugerir la presencia de lo perverso y malévolo dentro del seno de la inocencia. Según las siguientes palabras del narrador extradiegético de Los cuadernos, Lucrecia intuye en su hijastro esta misma naturaleza ambigua y amenazante: "No pudo contener la carcajada. Pero, la risa se le cortó de golpe, porque, como otras veces, intuyó que por debajo de lo que semejaba una niñería, podía anidar algo tenebroso” (200, el énfasis es mío). Además, el hecho de que las manos de Herbert adopten una posición fetal en el interior de esa especie de bolsa de líquido amniótico en la que flotan, iconografía muy similar a la representada en Death Mother I, Dead Mother II (The Birth of Genius) o Holy Family, alude sin duda a uno de los conceptos centrales en la cosmología del pintor: la equiparación del acto procreador con la creación artística (Kallir, Masterworks 42). El artista no sólo da a luz una obra de arte sino que se da a luz a sí mismo en el proceso creador: "In painting these 'Dead Mother' portraits of the earliest stages in his life, Schiele was not only telling us how he had to fight for his life; he was saying that he had to become his own creator” (Knafo 37). Rigoberto trata igualmente de reinventarse sin cesar, fantaseando ser otro u otros, travistiéndose en personajes creados por su imaginación. Este acto creador lo acerca a esos pintores y escritores admirados por él, por haber dado vida en sus libros y cuadros a esos personajes que pueblan su estudio y sus ensueños: "esa miríada de seres animados por la imaginación, los deseos y la destreza artística, presentes en los cuadros, libros y grabados que con paciencia y amor de muchos años había conseguido reunir” (19).

Con respecto a la composición de El retrato de Herbert Rainer, Frank Withford advierte que la figura de Herbert se perfila completamente aislada sobre un fondo blanquecino, que recalca su aislamiento e inadaptación social: "Schiele was probably not a pleasant child. He was certainly intensely lonely and withdrawn, fonder of daydreams than mundane reality and convinced that he was generally disliked and misunderstood” (30). Esta tendencia al aislamiento y a la ensoñación caracteriza asimismo a Rigoberto y a su hijo. El mayor placer de Rigoberto es recluirse de noche en su estudio para montar imaginariamente esos guiones eróticos en los que el papel estelar lo representa siempre su mujer (288). El mayor goce de Fonchito es pasar horas y horas encerrado en el salón de la casa del Olivar hablándole a su madrastra de la vida y obra de Schiele, comportamiento que Lucrecia considera anormal para un niño de su edad. 
La inclusión de una puerta entreabierta en la ilustración de la portada, además de estrategia técnica para iluminar la escena, pone el acento en un aspecto nodal con relación a la obra pictórica y narrativa de Schiele y Vargas Llosa, respectivamente: el ver y el ser/ saberse visto como fuente inagotable de placer. Claude Gandelman argumenta al respecto:

It may also be that doors in paintings are signs indicating that we the spectators are not only seeing but are being seen by the work of art. Doors are signs of the dialogic essence of art objects - to speak like Bakhtin. They speak to us about the dialectic of seeing, which always implies a being seen relationship (43).

Esta relación indisociable entre el ver y verse, entre el ver y ser visto, es acentuada en los dibujos de Schiele y en la ficción de Vargas Llosa por la mediación del espejo. El placer de esa mirada refleja y el placer de imaginar(se) se funden en la portada del libro a fin de seducir a los lectores y lectoras de Los cuadernos. Ante ese espectáculo erótico y sensual representado tras los bastidores de lo visible, el público lector se ve obligado a imaginar lo que sólo es sugerido, a completar lo no representado, a llenar imaginativamente con el suplemento derridiano el vacío de esa presencia borrada, del mismo modo en que Rigoberto ha de llenar el hueco dejado por el cuerpo de su mujer con sus "performances relatoras" nocturnas (132): "En verdad, aun en sus momentos más puros, su soledad había sido un desdoblamiento, una cita a la que Lucrecia nunca faltó” (130).

Tanto El retrato de Herbert Rainer como otros elementos iconográficos de la imagen de cubierta del libro (el camisón negro, el zapato rojo, la bata color crema, la iluminación y la composición de la imagen), funcionan como signos dentro de los sistemas semióticos que articulan el discurso narrativo y las reproducciones pictóricas de Los cuadernos. Estos signos transmiten algunos contenidos pertenecientes tanto al campo semántico y estructural de la novela como al papel del lector y lectora dentro de ella: sensualidad, hedonismo, erotismo, pintura, escritura, pluriperspectivismo, voyeurism, estimulación de la imaginación, desdoblamiento, teatralidad, recepción artística, relación entre la vida y el arte, etc.

Dentro del plano diegético de la novela, Schiele y su obra desempeñan diversas funciones en lo tocante a la caracterización de los personajes y a la narración misma. A través de esa voz narradora omnisciente que sobrevuela el tejido discursivo de la novela, saltando incesantemente de un punto de vista a otro, y reduplicando narrativamente esa perspectiva pictórica “de ave de presa” que caracteriza — según Fonchito— los bocetos y dibujos de Schiele (156), se nos da a conocer la inesperada llegada de Fonchito a la casa de la madrastra: "Llamaron a la puerta, doña Lucrecia fue a abrir y, retratada en el vano, con el fondo de los retorcidos y canosos árboles del Olivar de San Isidro, vio la cabeza de bucles dorados y los ojos azules de Fonchito” (10). El vano de la puerta funciona en esta descripción como el marco de un lienzo sobre el que se dibujara el rostro de Fonchito. El interés por capturar en el texto narrativo experiencias de orden perceptivo y sensual, y la percepción de la realidad exterior como si se tratara de un cuadro utilizando un lenguaje impregnado de las cualidades estilísticas del arte pictórico, es un recurso estilístico que impregnaba ya el tejido discursivo de Elogio y que es retomado en Los cuadernos. Los capítulos titulados "Las cositas de Schiele” (II), "El juego de los cuadros” (III), "Fonchito en lágrimas” (IV), "Fonchito y las niñas” (V), "El anónimo” (VI) y "El dedo gordo de Schiele” (VII), se inician con un 
segmento en el que un narrador extradiegético narra las visitas de Fonchito a la casa del Olivar, mezclando el diálogo con la narración en sí de los eventos. Escapándose de la academia de pintura a la que asiste tres días por semana, Fonchito acude clandestinamente a la casa de su madrastra arrastrando una carpeta en la que guarda sus propios dibujos y libros de reproducciones de las obras de Schiele: “Quiero mostrarte mis dibujos. Y que hablemos de Egon Schiele, de su vida y sus pinturas. Contarte lo que voy a ser de grande y mil cosas. ¿Ya lo adivinaste? ¡Pintor, madrastra! Eso quiero ser” (13). Las alusiones por parte de Fonchito al arte y vida de Schiele dependen de su conocimiento e interés por el pintor así como del uso específico que pretende darles. Fonchito menciona numerosos aspectos de la vida y obra de Schiele: las posturas, cuerpos forzados y dislocados de sus figuras (31), su vida de niño (35), la relación con sus modelos (36), la sífilis del padre (114), su obsesión por las niñas (153-54), su encarcelamiento por corrupción de menores (154), su afán por autorretratarse (200), su esquizofrenia (199), su manía por las manos (235), la importancia del espejo en su obra (275). Recurriendo al recurso técnico que el propio Vargas Llosa denominó como “técnica de los vasos comunicantes”, los acontecimientos, personajes y situaciones de la historia primaria (la historia familiar de Rigoberto, Lucrecia y Fonchito), se entretejen con los de la historia secundaria (la vida y arte de Egon Schiele). Fonchito y su padre tienen también esa misma costumbre de "entreverar la vida de los cuadros con la verdadera” (194). Fonchito le explica a Lucrecia su interés por Schiele con estas razones: “-Porque, siento que me le parezco. Que voy a tener una vida trágica, como la suya," infiriéndose de sus palabras la función profética del arte. Como a Schiele, a Fonchito le obsesiona la muerte, “ ¡No te mueras! le grita asustado a Lucrecia cuando la ve palidecer por la sorpresa de verlo” (9). Teme también que su padre enloquezca o muera de sífilis como el padre de Schiele: “El destino de su papá se está repitiendo en el mío —-balbuceó Fonchito” (114). Como a Schiele, se le tacha de corruptor: "Porque no había sido ella la corruptora, aunque la diferencia de edad la condenara; había sido él, él, el corruptor” (280). Fonchito se confiesa esquizofrénico como el pintor: "Yo soy como era él y lo sabes muy bien, porque acabas de decírmelo. Un viejo y un niño. Un angelito y un demonio. O sea esquizofrénico” (201). Y llega hasta creerse reencarnación suya: “—Es que yo soy él, madrastra. Aunque lo tomes a broma, es así. Siento que soy él.” (237). Este juego de reflejos compromete a Lucrecia y Rigoberto también. Fonchito identifica a la madrastra con la modelo del cuadro de Schiele Desnudo reclinado con medias negras:

—Qué coincidencia, madrastra- decía Fonchito, mientras hojeaba el libro de reproducciones de Schiele que acababa de sacar del bolsón-. Yo me parezco a él y tú te pareces a sus modelos. En muchas cosas.

—¿En qué, por ejemplo?

- En esas medias verdes, negras o marrones que te pones. También, en la frazada a cuadritos de tu cama.

—Caramba, qué observador.

—Y, por último, en la majestad — añadió Fonchito, sin levantar la vista, enfrascado en la búsqueda del Desnudo reclinado con medias verdes. [...] ¿No decía mi papá que tienes una majestad tan grande? ¿Que hagas lo que hagas, nada en ti es vulgar? Yo sólo entendí lo que quería decir gracias a Schiele. Sus modelos levantan las faldas, muestran todo, se las ve en posturas rarísimas, pero nunca parecen vulgares. Siempre unas reinas. ¿Por qué? Porque tienen majestad. Como tú, madrastra (76-77). 
Esta cita revela otra de las funciones que desempeña el arte de Schiele en cuanto a la caracterización del niño: le sirve de instrumento de conocimiento del mundo que le rodea, utilizándolo además para la obtención de sus propios fines. Gracias al arte de Schiele Fonchito se iguala a su padre suplantándolo como sujeto cuya mirada encasilla a Lucrecia en un objeto estético que le procura placer. Conocedor de esos "jueguecitos con cuadros" que tenían en las noches Rigoberto y Lucrecia, cuando ella imitaba las pinturas que su marido deseaba para materializar las fantasías eróticas de éste (197), Fonchito consigue que la madrastra imite para él el cuadro de Schiele intitulado Desnudo reclinado con medias verdes:

Trató de imitar la reproducción que Fonchito había desplegado y que le señalaba, como un director teatral instruyendo a la estrella del espectáculo [...]. “¿Es así la cosa? No más arribita la espalda, el cuello como gallinita, la cabeza derechita”, mientras se apoyaba en los codos, alargaba una pierna y flexionaba la otra, calcando la pose de la modelo (78).

Quizás el fondo edípico de este conflicto paterno-filial se refleje en el bajo concepto que a Rigoberto le merece el pintor: “‘ ¡Schiele!, pensó. Variante aviesa del impresionismo al que Oscar Kokoshka llamaba, con toda justicia, un pornógrafo’. Se descubrió poseído de un odio visceral, ácido, bilioso a Egon Schiele” (363).

Los desdoblamientos, travestismos y juegos de impostura que entretienen los personajes de la novela caracterizan, también, el arte de Egon Schiele. Al hablar del cuadro de Schiele, Cardinal and Nun, un cuadro considerado una bofetada sacrílega a la moralidad convencional de la época, Kallir afirma que dicho juicio sería acertado si se tratara de un cardenal y monja genéricos, pero que la identificación de Egon y Wally en los papeles estelares sugiere otra interpretación alegórica: “If Schiele was a priest of art, Neuzil was his natural helpmeet, his nun as it were” (Masterworks 42).

El arte de Schiele desempeña un papel esencial en el desarrollo de la trama. Fonchito se sirve de Schiele como coartada para sus frecuentes visitas a la casa del Olivar. Mientras Lucrecia se va dejando envolver en esa telaraña discursiva que el niño teje en torno a Schiele con su destreza “de buen contador" (367), Fonchito se sirve de Schiele para revivir la sensualidad de su madrastra, que la conducirá de nuevo a los brazos de Rigoberto. La obra de Schiele opera como fuente de inspiración para el amor y acicate del deseo sexual, dando prueba de "la capacidad persuasiva que tiene una obra de arte” (303) y del poder afrodisíaco de la narración.

La obra de Schiele ayuda también a desentrañar ciertos misterios de la trama novelística. Gracias al cuadro de Schiele intitulado Schiele, Drawing a Nude Model before a Mirror Lucrecia atribuye a Fonchito la autoría de los anónimos que ha estado recibiendo: “-Te ha delatado tu maldito espejo, tu maldito Schiele” (279), le grita al niño al darse cuenta de que es él quien le ha escrito el anónimo pidiéndole que imite a Moa, la modelo que posó en dicho cuadro. Irónicamente, Schiele también termina delatando a Lucrecia. Tras su reconciliación, Lucrecia le confía a Rigoberto su honda preocupación por la obsesión enfermiza que Fonchito tiene con Egon Schiele, lo cual levanta las sospechas de Rigoberto, quien ignoraba las visitas de su hijo a la casa del Olivar: "Don Rigoberto no se rió. ... ¿Cómo se había enterado Lucrecia de que Fonchito sabía tantas cosas sobre Egon 
Schiele?” (363). Dentro del plano diegético, por tanto, la vida y obra de Schiele contribuyen a caracterizar a los personajes, las relaciones entre ellos y el mundo en el que se desenvuelven, a urdir la intriga y a propulsar la acción hasta su precaria resolución final.

A nivel temático, las pinturas de Schiele operan como significantes de temas recurrentes tanto en el arte de Schiele como en Los cuadernos de Vargas Llosa: énfasis en la sensualidad y el erotismo, signos de una sexualidad abigarrada, soledad y aislamiento, representación del cuerpo femenino, y relación del arte y del artista con la sociedad. Las imágenes autistas de Schiele y su obsesión por su propio ser fragmentado se reflejan en el narcisismo exorbitante tras del cual se amurallan Rigoberto y Fonchito, que es, paradójicamente, un narcisismo poblado de numerosos fantasmas: "A don Rigoberto se le llenaron los ojos de lágrimas. Redescubrió el terso silencio de la noche barranquina y la soledad en que se hallaba, entre grabados y libros autistas” (186).

La imaginación, el arte, la memoria y el erotismo funcionan en esta novela como una puerta por la que Rigoberto escapa del confinamiento de su estudio, y con él, el público lector de la novela:

Y una vez más sintió en el fondo de su corazón brotar, como un surtidor de agua clara, un tierno sentimiento de gratitud hacia esas profundidades de la memoria de las que inagotablemente estaban manando sorpresas, imágenes, fantasmas, sugerencias, para dar cuerpo, escenario y anécdota a los sueños con los que se defendía de la soledad, de la ausencia de Lucrecia (340).

Los temas mencionados nos introducen en el marco ideológico de la novela. Según Marianna Torgovnick, “An ideological use of the visual arts embodies major themes of the fiction — especially its views of politics, history, society, or, more generally, of 'reality' in descriptions, objects, metaphors, artist figures, or scenes based upon the historical visual arts or experienced pictorially" (19). Dentro de este marco, voy a referirme a dos aspectos: la representación pictórica y discursiva de la mujer, y el papel del artista y del arte en la sociedad.

Los cuadernos, como continuación de Elogio, supone la prolongación del placer mediante su postergación y sabia dosificación. Es sugestivo ver una alusión a esta función hedonista y lúdica de Los cuadernos en el comentario que hace don Rigoberto sobre las estrategias amatorias que Lucrecia emplea con su amante imaginario, Modesto (Pluto):

—Con cada cosa que me cuentas, pienso mejor de él — comentó don Rigoberto.

— Me pasaba lo mismo — reconoció doña Lucrecia. —Y, por eso, ese día, di un pasito más para premiarlo. En Maxim's, sintió mi rodilla en la suya toda la comida. Y, cuando bailamos, mis pechos. Y en el Crazy Horse, mis piernas.

—Quién como él —exclamó don Rigoberto-. Irte conociendo tipo serial, por episodios, pedacito a pedacito (62, el énfasis es mío).

Esta promesa de goce sexual está ligada también a la promesa de conocimiento, posesión que — según Freedberg — revela la base erótica de toda verdadera comprensión: "The hermeneutic quest is always founded on the repression and perversion of desire, the objects of understanding are always bare” (317) y con frecuencia, femeninos: "Women 
displayed as sexual object is the leitmotif of erotic spectacle” (Mulvey 1448). El placer sexual y estético, como "tierra prometida" hacia la que se encamina Pluto, es compartido también por los lectores y lectoras que estén dispuestos a asumir o cuestionar esta perspectiva predominantemente masculina que prevalece en la novela. Puede que Lucrecia descubra el placer en esas noches lúdicas compartidas con su esposo, en las que aparece transformada en ávida narradora de ensueños eróticos y adiestrada actriz dentro de los montajes pornográficos que coreografía su marido. Sin embargo, el detonador que la hace estallar de placer, no lo son ni sus propias fantasías ni sus propios deseos, sino las fantasías y deseos de otros, de Fonchito, de Justiniana, y sobre todo de su marido. La naturaleza dependiente de Lucrecia se refleja en la descripción que Rigoberto hace de sí mismo y de su mujer. Rigoberto se describe así: “el reconstructor de tu identidad, el pintor que te deshace y te rehace a su capricho, tu desvelado soñador” (148), y describe a su mujer en los siguientes términos: “¡Cara Lucrecia! Entre todas las gracias que la adornan, ninguna agradezco tanto como su compresión de mis debilidades, su sabiduría para ayudarme a cuajar mis fantasías” (210, énfasis mío). Luce Irigarary arguye al respecto:

Woman, in this sexual imaginary, is only a more or less complacent facilitator for the working out of man's fantasies. It is possible, and even certain, that she experiences vicarious pleasure then, but this pleasure is above all a masochistic prostitution of her body to a desire that is not her own and that leaves her in her well-known state of dependency (1468).

Este estado de dependencia por parte de Lucrecia es puesto claramente de manifiesto al término de la novela, al confesarle a su marido la naturaleza débil de su carácter y la necesidad de que éste la vigile constantemente para que no caiga de nuevo en esa tentación que encarna Fonchito: "Si no quieres que pase otra vez, vigílame, célame, acósame. No quiero acostarme nunca con nadie más, sólo contigo, maridito querido” (374). ${ }^{10}$

Egon Schiele y Los cuadernos convergen en algunas asunciones con respecto al papel del artista y del arte en la sociedad: el poder redentor del arte, el arte como refugio, el arte como desafío a nuestra mortalidad, el arte como acicate de la imaginación y molde en el que se materializa el deseo según determinadas pautas estéticas. Como en obras anteriores, en Los cuadernos Vargas Llosa indaga acerca de la creación y recepción artísticas. Contemplar el mundo no quiere decir en Los cuadernos "ver" el mundo sino imaginarlo. Se trata de imaginar un mundo en el que se materialice el deseo y de crear ese mundo imaginado por medio del lenguaje, la impostura y la imitación artística, de manera que éste recobre una presencia física. El sujeto de dicho discurso es un sujeto que contempla e imagina, y al contemplar e imaginar crea: "The eye is a tactile creature, an agent of human contact. By virtue of its mere touch, the eye gives live” (Claude Gandelman 1). El poder creador del artista, como comenté anteriormente, constituye el centro de la cosmogonía pictórica de Schiele. Rigoberto exalta la imaginación creadora como el reino privilegiado de la libertad.

\footnotetext{
${ }^{10}$ Un atento estudio de esta novela sobre las diferentes formas de representación narrativa y pictórica, guiado tanto por los hallazgos de la semiología de la imagen como por los de la crítica feminista, contribuiría sin duda a problematizar y replantear este debate respecto a la masculinización del sujeto y de la mirada en la historia del arte occidental y de la literatura erótica.
} 
No obstante, su imaginación es una imaginación “invadida por deseos teatral-copulatorios” (287) y colonizada no sólo por el cuerpo de su mujer ("el cuerpo de Lucrecia fue colonizando su conciencia” 349), sino por otros dogmas éticos y estéticos como su proclamada monogamia ("Es que, yo, yo, cómo decírtelo, soy monógamo. Sólo puedo hacer el amor con mi mujer” 147) y su lealtad a cánones estéticos establecidos que esculpen sus fantasías eróticas (“el modelo clásico, la gran tradición” 264). ${ }^{11}$

La suma libertad en el ámbito del placer que Rigoberto defiende a toda ultranza, se ve asimismo coartada por su fobia a las masas, que limita a cuatro el número de participantes en cualquier juego amatorio, para no caer en la aberrante orgía colectiva. Rigoberto, llega incluso a comprometer seriamente la libertad artística, tantas veces defendida en sus arengas contra el gregarismo, al sentenciar dogmáticamente que "la obligación de un cuadro" es excitarlo, careciendo de lo contrario de interés (287), y al establecer su criterio de valoración artística como un traje hecho a su propia medida: "todo lo que yo podría hacer en materia plástica o escultural es una mierda. Sólo califican, pues, los artistas cuyas obras están fuera del alcance de mi mediocridad creativa, aquellos a los que yo no podría reproducir” (287). No obstante, Rigoberto es consciente de sus excesos y contradicciones, que en lugar de avergonzarlo lo enorgullecen, según le explica al rotario en uno de sus soliloquios epistolares: “¿Y, entonces? ¿En qué quedamos? Yo no sé en qué quedarás tú, querido colega (para usar otra expresión vomitable). Yo me quedo en mi contradicción, que es, también, después de todo, una fuente de placer para un espíritu díscolo e inclasificable como el mío” (170).

Tampoco hay que olvidar que, para Rigoberto, la intensidad del placer es proporcional al grado de la transgresión, ética más que estética, que requiere la materialización de los deseos:

una vida mental rica y propia exige curiosidad, malicia, fantasía y deseos insatisfechos, es decir, una mente "sucia”, malos pensamientos, floración de imágenes prohibidas, apetitos que induzcan a explorar lo desconocido y a renovar lo conocido, desacatos sistemáticos a las ideas heredadas, los conocimientos manoseados y los valores en boga (128).

Sin límites, por tanto, quedaría anulado el enorme goce que procura el desafío de esos mismos límites (aun si dicha transgresión se opera exclusivamente en el dominio de la imaginación): "es cierto también, que, sin prohibiciones, pecados, fulminaciones morales, los deseos — el deseo sexual sobre todo — no hubiera alcanzado el refinamiento que tuviera en ciertas épocas”, concede Rigoberto en su carta al rotario (169).

Sin Fonchito, Rigoberto tampoco sería capaz de experimentar el dolor que va aunado al goce transgresor. Rigoberto y Fonchito son uno y el mismo, un "Fonchito-niño-casi hombre o ... un Rigoberto-joven-casi niño” (322), como califica Lucrecia a ese Schiele reencarnado con quien se da cita en el hotel Sheraton en la única "performance relatora” de Fonchito, copia exacta de las de su padre. Refiriéndose al arte de Schiele, Danielle Knafo

\footnotetext{
${ }^{11}$ Por ejemplo, Lucrecia le declara a Fonchito que aunque de joven era delgada, engordó para dar gusto a Rigoberto, ya que para él la tradición de la belleza es ubérrima, de formas orondas pero sin llegar a la obesidad (Rubens, Coubert...) (233).
} 
alude, también, a esta compleja fusión o juego de identidades padre-hijo, niño-adulto, que caracteriza la relación de Rigoberto con su hijo:12

\begin{abstract}
Schiele's art is indeed an art of survival and the self he unashamedly shows us is that of a survivor. He expresses the malaise of his times, the oppressive fate of modern man. Although his art is clearly self-obsessed, it is a mistake to think it vain. Rather, Schiele wounds himself to the point of turning himself into a grotesque creature in order to simultaneously express the plight of an adult man who suffered from the indifference of his surroundings and an infant whose needs are experienced as overwhelming and monstrous (21).
\end{abstract}

Con el fin de problematizar modas y modos de pensar y actuar en nuestra sociedad de finales de siglo, Mario Vargas Llosa crea un personaje de dos caras (padre-hijo, niñoadulto), en el que proyecta sus propias inquietudes de un modo tan hiperbólico y cómico, que hace de don Rigoberto un personaje hermosamente grotesco, al exaltar "hasta extremos deicidas el derecho del ser humano de insurgir contra lo establecido" (300) en pos de su fe ciega en esa inseparable trinidad: individualidad, racionalidad y libertad (248).

Por una parte, en Los cuadernos el discurso narrativo se esfuerza por concretizar lo más abstracto, por materializar las fantasías eróticas de Rigoberto, recurriendo a un lenguaje impregnado de las cualidades estéticas del arte pictórico. Por otra, las imágenes pictóricas sirven de trampolín a la imaginación del personaje, al vuelo de su fantasía. El arte y la vida, la realidad y el deseo se fusionan en esa otra realidad que Rigoberto urde en su imaginación y que desbordándose del vaso que la contiene, salpica y transfigura a su vez su vida ordinaria. Dentro de ese juego de reflejos y contrarreflejos que entretiene esta novela, el siguiente comentario sobre El diario de Edith de Patricia Highsmith, que Rigoberto anota en sus cuadernos, se refiere de modo metaficticio a Los cuadernos: "La novela está construida con simplicidad engañosa, bajo la cual se perfila un contexto dramático, de lucha sin cuartel entre las hermanas enemigas, la realidad y el deseo, y las infranqueables distancias que las separan, salvo en el recinto milagroso del espíritu humano” (222). De la misma manera en que Egon Schiele comparte su intimidad y la de sus modelos con quienes contemplan sus cuadros, de la misma manera en que Rigoberto comparte la intimidad de sus juegos eróticos con el narrador extradiegético de la novela y con esos "movibles y transitorios figurantes" de su imaginación (333), de la misma manera en que Lucrecia comparte la intimidad de su cuerpo con Nepuceno, "luciendo esa intimidad tan íntima” ante él (22), de la misma manera en que Fonchito comparte la intimidad "tumbal" de los cuadernos con su padre, sin que éste lo sepa (210), Mario Vargas Llosa comparte con los lectores y lectoras de Los cuadernos la intimidad de "ese recinto milagroso del espíritu humano” en el que reina la imaginación.

Rigoberto edifica su casa, “ese espacio construido” que llamará su mundo (16), para alojar sus libros, cuadros y grabados, según le confiesa a su arquitecto en una de las cartas

\footnotetext{
${ }^{12}$ Este juego de identificaciones padre-hijo es recurrente en toda la novela: ambos comparten el hábito de fantasear (116), ambos son imaginativos (100), la sicología de ambos es enrevesada (156), ambos son anti-sociales, ambos esquizofrénicos (262), ambos comparten la misma fascinación por la pintura (194), etc.
} 
que recogen sus cuadernos: “Construyo esta casa para padecer y divertirme con ellos, por ellos y para ellos. Haga un esfuerzo por imitarme en el limitado período que trabajará para mí. Ahora dibuje” (19). Mario Vargas Llosa, por su parte, construye esta novela para dar alojamiento a los personajes de su imaginación. Plagiando a su personaje, el autor parece hacernos a nosotros, lectores y lectoras del libro, una confesión similar: “construyo esta novela para padecer y divertirme con ellos, por ellos y para ellos. Haga un esfuerzo por imitarme en el limitado período que durará su lectura. Ahora lea y goce”. Aunque ese gozo, al igual que la felicidad, la vida misma o la lectura, sea tan evanescente y fugaz como la llama de las velas que alumbran la belleza de esas María Magdalenas penitentes del pintor francés Georges de La Tour (1593-1652). Según Rigoberto: "tenemos que reavivarla, de tiempo en tiempo, no permitir que se apague, soplando la llamita” (377).

\section{OBRAS CITADAS}

Benjamin, Walter. "La obra de arte en la época de su reproductibilidad técnica”. Discursos interrumpidos I. Madrid: Taurus, 1973. 15-57.

Berger, John. Ways of Seeing. Londres: The British Broading Corporation and Penguin Books, 1972.

Feal, Rosemary Geisdorfer y Carlos Feal. Painting on the Page. Interartistic Approaches to Modern Hispanic Texts. Albany: State University of New York Press, 1995.

Fischer, Wolfgang Georg. Egon Schiele 1890-1918. Desire and Decay. Köln: Taschen, 1998.

Gandelman, Claude. Reading Pictures, Viewing Texts. Bloomington y Indianapolis: Indiana University Press, 1991.

Genette, Gérard. Figures II. París: Seuil, 1969.

Irigaray, Luce. “This Sex Which is not One”. The Critical Tradition. David E. Richter, ed. y Claudia Reeder, trad. Segunda edición. Boston: Bedford Books, 1998. 1466-71.

Kallir, Jane. Egon Schiele: The Complete Works. Nueva York: Harry N. Abrams, 1990. 27 Masterworks. Nueva York: Harry N. Abrams, 1995.

Knafo, Danielle. Egon Schiele. A Self in Creation. A Psychoanalytic Study of the Artist's Self-Portraits. Londres y Toronto: Associated University Presses, 1993.

Lund, Hans. Text as Picture. Studies in the Literary Transformation of Pictures. Kacke Götrick, trad. Lewiston: The Edwin Meller Press, 1992.

Mitchell, W. J. Thomas. Picture Theory: Essays on Verbal and Visual Representation. Chicago: University of Chicago Press, 1994.

Mulvey, Laura. "Visual Pleasure and Narrative Cinema”. The Critical Tradition. David E. Richter, ed. Segunda edición. Boston: Bedford Books, 1998. 1444-53.

Steiner, Wendy. The Colors of Rhetoric. Problems in the Relation between Modern Literature and Painting. Chicago y Londres: The University of Chicago Press, 1982.

Torgovnick, Marianna. The Visual Arts, Pictorialism, and the Novel: James, Lawrence, and Woolf. Princenton: Princenton University Press, 1985.

Vargas Llosa, Mario. Elogio de la madrastra. Barcelona: Tusquets, 1988. Los cuadernos de don Rigoberto. Madrid: Alfaguara, 1997. 
Wagner, Peter. European Culture Studies in Literature and the Arts. Icons-TextsIconotexts: Essays on Ekphrasis. Berlin y Nueva York: Walter de Gruyter, 1996.

Wilson, Simon. Egon Schiele. Londres: Phaidon, 1993.

Witford, Frank. Egon Schiele. Londres: Thames and Hudson, 1981.

Wolf, Bryan. "Confessions of a Closet Ekphrastic”. Yale Journal of Criticism 3/2 (1990): 181-204.

Zunzunegui, Santos. Pensar la imagen. Madrid: Cátedra, 1992. 